\title{
PENERAPAN SISTEM AKUNTANSI PENERIMAAN KAS DARI PENJUALAN TUNAI (STUDI KASUS PADA CV RESTU IBU BANJARMASIN)
}

\author{
YULI FITRIYANI \\ Jurusan Teknologi Industri Pertanian, Politeknik Negeri Tanah Laut \\ Jl. A. Yani, km 06, Ds. Panggung, kec. Pelaihari, Kab. Tanah Laut, Kalimantan Selatan \\ e-mail:yulifitriyani_math@yahoo.com
}

\begin{abstract}
Abstrak
Kas memiliki peranan yang sangat penting dalam kegiatan operasional di segala bidang usaha baik itu usaha kecil, menengah maupun besar. Hampir setiap hari kas selalu digunakan dalam berbagai transaksi penjualan maupun pengeluaran biaya. Oleh karena itu, didalam transaksi penjualan perlu adanya prosedur dan pencatatan yang baik guna mengetahui berapa besar penerimaan kas yang diperoleh dari hasil penjualan barang tersebut. Kerangka pemikiran penelitian ini meliputi: sistem akuntansi, sistem pengendalian intern terhadap sistem penerimaan kas. Sistem pengendalian intern mempunyai tujuan menjaga kekayaan organisasi, untuk itu harus ada pemisahan fungsi-fungsi agar tidak terjadi penyelewengan terhadap kas perusahaan.Harus ada sistem otorisasi dan prosedur pencatatan agar pemakaiannya dapat dipertanggungjawabkan oleh pihak yang berwenang.

Dari hasil penelitian disimpulkan bahwa di dalam penanganan transaksi sistem akuntansi penerimaan kas dari penjualan tunai sebaiknya dilakukan pemisahan fungsi antara fungsi penjualan, fungsi kasir dengan fungsi akuntansi dengan menambah karyawan agar perusahaan tersebut dapat bejalan dengan baik begitu juga dalam rangka melindungi atau menjaga uang kas yang dimiliki CV Restu Ibu Banjarmasin, maka sebaiknya uang kas yang diterima segera disetorkan ke bank secara periodik.
\end{abstract}

Kata kunci: kas, sistem akuntansi, sistem penerimaan kas, sistem pengendalian intern

\section{PENDAHULUAN}

Semakin meningkatnya persaingan dalam dunia usaha akibat perubahan ekonomi yaitu dengan meningkatnya harga-harga menjadikan manajemen perusahaan perlu membuat strategi baru agar perusahaannya mampu bertahan dan berkembang dalam tingkat persaingan yang ada. Setiap perusahaan memerlukan informasi yang dapat membuka jalan menuju kesuksesan yang diharapkan. Oleh karena itu, untuk dapat menghasilkan informasi akuntansi yang relevan diperlukan sistem akuntansi yang mendukung. 
Agar memenuhi kebutuhan informasi bagi pihak luar maupun dalam perusahaan, disusun suatu sistem akuntansi. Sistem ini direncanakan untuk menghasilkan informasi yang berguna baik pihak luar maupun dalam perusahaan.Sistem akuntansi itu sendiri adalah formulir-formulir, catatan-catatan, prosedur-prosedur dan alat-alat yang digunakan untuk mengolah data mengenai usaha suatu kesatuan ekonomis dengan tujuan untuk menghasilkan umpan balik dalam bentuk laporan-laporan yang diperlukan manajemen untuk mengawasi usahanya dan bagi pihak-pihak lain yang berkepentingan seperti pemegang saham, kreditur dan lembaga-lembaga pemerintah.

Penjualan tunai yang dilakukan oleh CV Restu Ibu Banjarmasin dengan cara mewajibkan pembeli langsung melakukan pembayaran harga barang terlebih dahulu sebelum barang diserahkan oleh perusahaan kepada pembeli dan transaksi penjualan tunai dicatat secara sederhana oleh perusahaan.

Berikut adalah gambaran tingkat penjualan perbulan dalam bentuk diagram oleh CV Restu Ibu Banjarmasin selama tahun 2010, 2011 dan 2012.

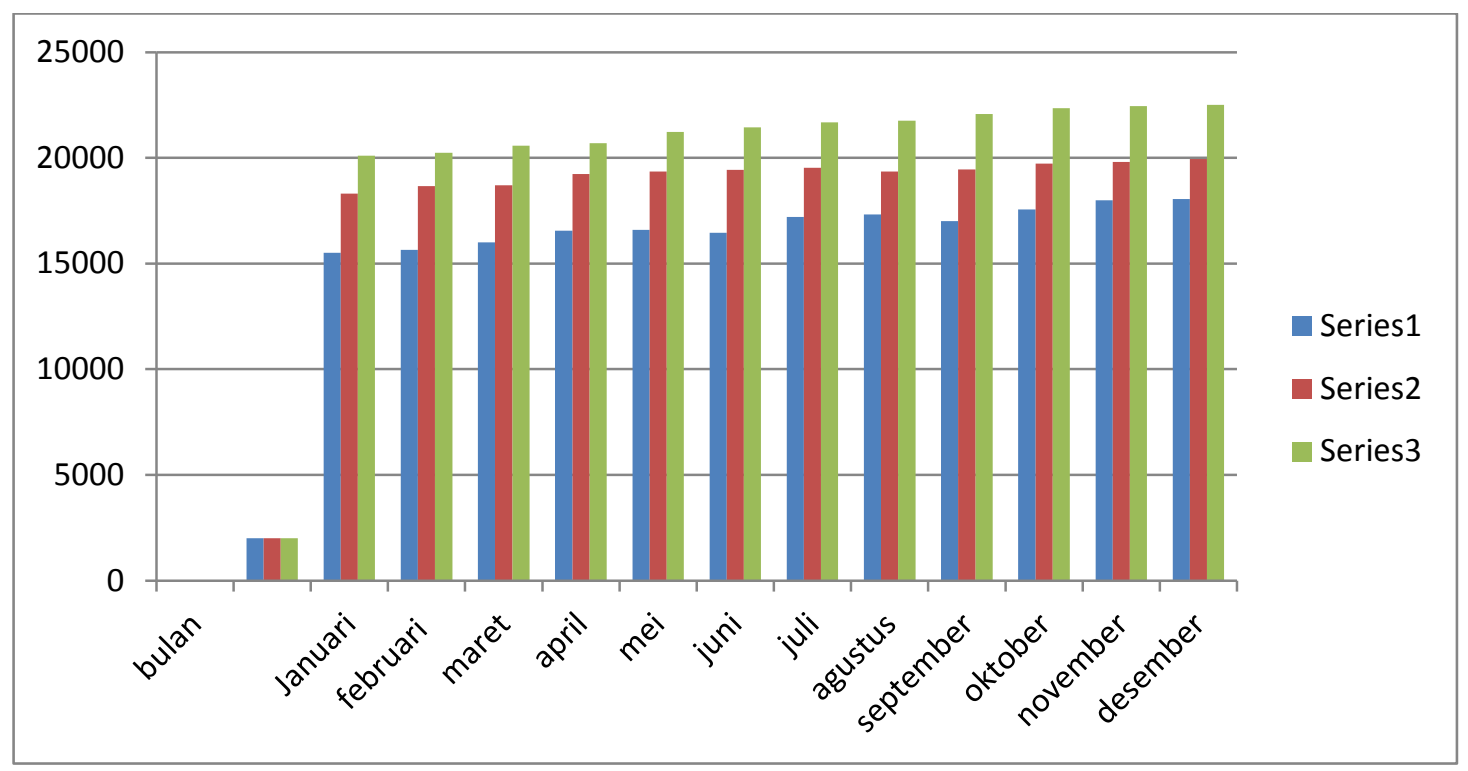

Sumber: Data Diolah

Dari diagram di atas, dapat dianalisis bahwa omzet penjualan terus meningkat selama tahun 2010 hingga tahun 2012 dipandang perlu untuk membuat sistem penerimaan kas yang akan memudahkan pimpinan dalam menjalankan dan mengawasi kegiatan operasional harian perusahaan.

Dengan meningkatnya volume penjualan tunai maka akan sangat mempengaruhi frekuensi dan volume penerimaan kas pada perusahaan. Karena tidak adanya pemisahan 
fungsi, maka fungsi penjualan yang merangkap dengan fungsi kas dan fungsi akuntansi oleh pimpinan dirasakan semakin berat dan tidak bisa ditangani sendiri oleh pimpinan.

Penerapan sistem dan prosedur akuntansi yang baik akan sangat berpengaruh terhadap penerimaan kas. Dengan adanya sistem dan prosedur akuntansi yang baik akan membantu CV Restu Ibu Banjarmasin untuk mencapai tujuan pengendalian intern akuntansi yaitu menjaga kekayaan organisasi, mengecek ketelitian dan keandalan data akuntansi (Mulyadi, 2005). Untuk pencapaian tujuan tersebut perlu adanya karakteristik sistem akuntansi yang baik dalam perancangannya.

Karakteristik sistem akuntansi yang baik adalah struktur organisasi yang memisahkan tanggung jawab fungsional secara tegas, sistem wewenang dan prosedur pencatatan yang memberikan perlindungan yang cukup terhadap kekayaan, utang, pendapatan dan biaya, praktik yang sehat dalam melaksanakan tugas dan fungsi setiap unit organisasi, serta karyawan yang mutunya sesuai dengan tanggung jawabnya. Apabila karakteristik ini telah dilaksanakan dan terpenuhi maka kegiatan operasional dalam perusahaan dapat berjalan dengan baik.

\section{Sistem Akuntansi Penerimaan Kas}

Sistem menurut (Mulyadi, 2005) adalah "sekelompok unsur yang erat berhubungan satu dengan yang lainnya, yang berfungsi bersama-sama untuk mencapai tujuan tertentu”. Menurut (Baridwan, 2009) “Kas merupakan suatu alat pertukaran dan juga digunakan sebagai ukuran dalam akuntansi.Kas merupakan aktiva perusahaan yang paling penting diantara aktiva lainnya dan dapat pula digunakan untuk membeli barang dan jasa, serta memenuhi kewajiban dengan perusahaan". Sistem akuntansi penerimaan kas adalah penerimaan oleh perusahaan yang berasal dari kegiatan operasional perusahaan baik dari penjualan tunai maupun dari penagihan piutang.

Menurut (Baridwan, 2009) Dalam penerapan sistem penerimaan kas dari penjualan tunai biasanya terdiri dari unsur-unsur sebagai berikut: Fungsi yang terkait dalam sistem penerimaan kas dari penjualan tunai adalah: (1) Fungsi Penjualan, fungsi ini bertanggung jawab untuk menerima order dari pembeli, mengisi faktur penjualan tunai dan menyerahkan faktur tersebut kepada pembeli untuk kepentingan harga barang ke fungsi kas. (2) Fungsi Kas, fungsi ini bertanggung jawab sebagai penerima kas dari pembeli. (3) Fungsi Gudang, fungsi ini bertanggung jawab untuk menyiapkan barang yang dipesan oleh pembeli serta menyerahkan barang tersebut ke fungsi pengiriman. (4) 
Fungsi Pengiriman, fungsi ini bertanggung jawab untuk membungkus barang dan menyerahkan barang yang telah dibayar kepada pembeli. (5) Fungsi Akuntansi, fungsi ini bertanggung jawab sebagai pencatat transaksi penjualan dan penerimaan kas dan membuat laporan penjualan.

Dokumen yang digunakan dalam sistem penerimaan kas dari penjualan tunai adalah: (1) Faktur Penjualan tunai; (2) Bukti setor Bank; (3) Rekap harga pokok penjualan.

Catatan akuntansi yang digunakan: (1) Jurnal penjualan; (2) Jurnal penerimaan kas, (3) Jurnal umum, (4) Kartu persediaan, (5) Kartu gudang.

Jaringan prosedur yang membentuk system: (1) Prosedur order penjualan, (2) Prosedur penerimaan kas, (3) Prosedur penyerahan barang, (4) Prosedur penjualan tunai, (5) Prosedur penyetoran kas ke bank.

\section{METODE PENELITIAN}

Penelitian ini menggunakan model penelitian data kuantitatif yaitu data harga penjualan tahun 2010, 2011, 2012 dan data kualitatif yang nilainya tidak dinyatakan dalam bentuk angka dan lebih didasarkan padapertimbangan karakteristik perusahaan dan besar kecilnya usaha serta kebijakan akuntansi yang dipakai.

\section{HASIL DAN PEMBAHASAN}

\section{Sejarah Singkat Perusahaan}

CV Restu Ibu Banjarmasin merupakan perusahaan distributor yang bergerak dibidang perdagangan yang menjual berbagai macam ban bermerek Mizzle, selain menjual ban perusahaan tersebut menjual produk lain seperti oli eneos, oli top 1 dan accu (aki). CV Restu Ibu Banjarmasin didirikan pada tanggal 24 Juni 2001 oleh Bapak Mochammad Sairoji selaku pimpinan. Adapun perusahaan yang dipimpin mempunyai tujuan untuk mendapatkan keuntungan semaksimal mungkin.

Dalam menjalankan usahanya CV Restu Ibu Banjarmasin mendapatkan Surat Izin Usaha Perdagangan (SIUP) nomor 545.2.014/PU/DPE/2002. CV Restu Ibu Banjarmasin memiliki 6 (enam) orang karyawan yaitu 1 (satu) orang pimpinan selaku pemilik perusahaan yang merangkap sebagai fungsi penjualan, fungsi kas, 1 (satu) 
orang kepala toko selaku pembantu pimpinan dan mengawasi barang, 2 (dua) orang pada fungsi gudang dan 2 (dua) orang pada fungsi pengiriman. Lokasi CV Restu Ibu Banjarmasin di Jalan Simpang GustiNo. 55 Banjarmasin, Kalimantan Selatan.

\section{Struktur Organisasi}

Fungsi struktur organisasi dalam perusahaan sangat pentingguna mempertegas kedudukan, wewenang dan tanggung jawab masing-masing fungsi guna memperlancar proses pelaksanaan perintah dalam suatu organisasi. Struktur organisasi ini juga memperjelas uraian kerja dalam perusahaan.

Setiap perusahaan baik besar maupun kecil tentu memerlukan suatu struktur organisasi yang sesuai dengan jenjang pengawasan masing-masing untuk mencapai tujuan yang ingin dicapai. Semakin besar suatu perusahaan, maka akan semakin komplek masalah yang dihadapi perusahan tersebut, sehingga perusahaan semacam itu memerlukan struktur organisasi yang lebih rapi dan terencana.

Sedangkan perusahaan menegnah kebawah pada umumnya memiliki struktur yang lebih sederhana, karena ruang lingkup usahanya tidak terlalu luas dan penangannya tidak memerlukan karyawan yang terlalu banyak namun ada pemisahan tugas untuk masing-masing karyawannya.

Sistem tenagakerjaan pada CV Restu Ibu Banjarmasin adalah sebagai berikut: Pimpinan/pemilik/penjualan/kas/akuntansi: 1 orang

Kepala Toko/pembantu pimpinan/pengawasan barang: 1 orang Fungsi Gudang: 2 orang Fungsi Pengiriman: 2 orang

CV Restu Ibu Banjarmasin mempunyai bentuk organisasi yang sederhana, dapat dilihat dari struktur organisasinya yaitu pada Bagan 1. 


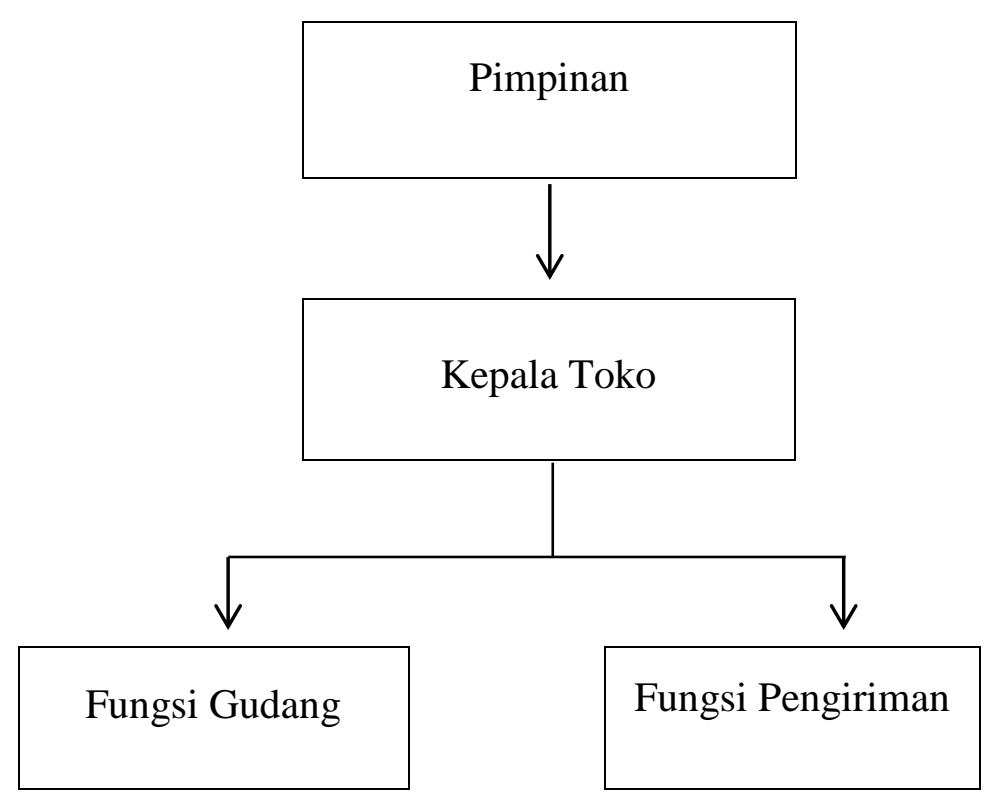

Bagan 1 Struktur Organisasi CV Restu Ibu Banjarmasin Sumber: Data Diolah

Dilihat dari struktur organisasi dan tugas-tugas karyawan sebaiknya dilakukan pemisahan fungsi-fungsi agar dapat mengefektifkan semua karyawan dan agar tidak terjadi lagi perangkapan fungsi maka sebaiknya fungsi kas ditangani sendiri oleh pimpinan supaya tidak terjadi penyelewengan terhadap kas perusahaan yang dapat dilakukan oleh karyawan lain. Mengefektifkan kepala toko (wakil pimpinan) untuk menangani fungsi akuntansi karena wakil pimpinan sudah mempunyai keahlian dalam pencatatan, penerimaan uang dan melayani pembeli bilamanpimpinan tidak ada ditempat.Untuk fungsi penjualan sebaiknya ditangani oleh salah satu dari fungsi gudang atau fungsi pengiriman.Penulis menyarankan untuk mengubah fungsi dan tugas masingmasing karyawan pada struktur organisasi. Adapun fungsi dan tugas yang disarankan pada struktur organisasi terlihat pada bagan 2 sebagai berikut: 


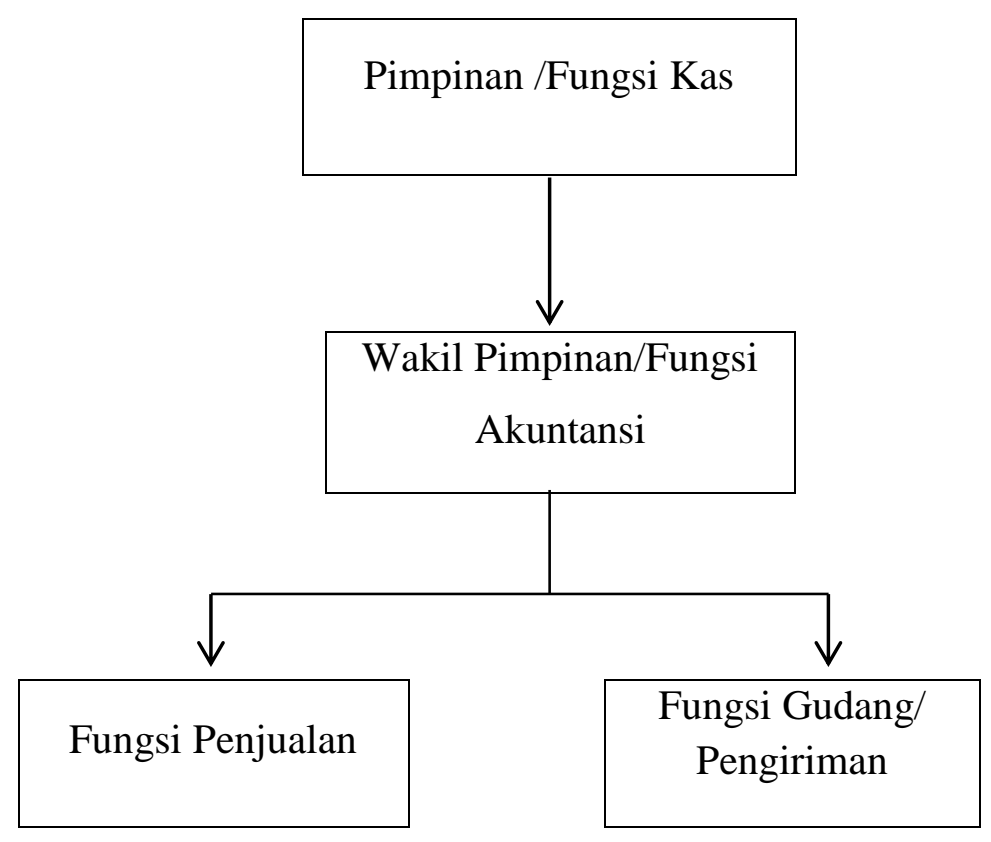

Bagan 2 Struktur Organisasi CV Restu Ibu Banjarmasin yang Disarankan

Penerapan Sistem Akuntansi Penerimaan Kas dari Penjualan Tunai yang Disarankan:

Prosedur penerimaan kas merupakan serangkaian kegiatan yang diawali dengan adanya penerima pesanan, penerimaan uang, pencatatan masuknya uang tersebut hingga penyimpanan uang.

\section{Catatan Akuntansi yang Disarankan}

Untuk mengatasi kesulitan yang disebabkan karena penggabungan buku tersebut, disarankan untuk memisahkan pencatatan penerimaan kas. Adapun catatan yang disarankan penulis adalah sebagai berikut:

\section{(1) Buku Kas}

Buku kas dalam perusahaan CV Restu Ibu Banjarmasin sebaiknya dikerjakan oleh fungsi kasir yang ahli bidangnya. Sehingga dapat terfokus dalam membukukan kas dan tidak terjadi kesalahan dalam pengurangan dan penjumlahan kas.

\section{(2) Jurnal Penjualan}

Jurnal penjualan disini memiliki manfaat atau kelebihan diantaranya selain mencatat dan meringkas data, disamping itu memungkinkan perusahaan untuk menggunakan karyawan dalam mencatat dengan segera transaksi keuangan yang terjadi. 
Tabel 1

Jurnal Penjualan yang Disarankan

\begin{tabular}{|c|c|c|c|c|c|c|c|}
\hline \multicolumn{8}{|c|}{$\begin{array}{l}\text { CV Restu Ibu Banjarmasin } \\
\text { Jurnal Penjualan } \\
\text { Juli } 2013\end{array}$} \\
\hline \multirow[t]{2}{*}{ Tanggal } & \multirow[t]{2}{*}{ Keterangan } & \multirow{2}{*}{$\begin{array}{l}\text { No. } \\
\text { Bukti }\end{array}$} & \multirow{2}{*}{$\begin{array}{c}\text { Piutang } \\
\text { Dagang } \\
\text { Debit }\end{array}$} & \multirow{2}{*}{$\begin{array}{c}\text { Penjualan } \\
\text { Tunai } \\
\text { Debit }\end{array}$} & \multicolumn{2}{|c|}{ Lain-lain Debit } & \multirow{2}{*}{$\begin{array}{c}\text { Hasil } \\
\text { Penjualar } \\
\text { Kredit }\end{array}$} \\
\hline & & & & & $\begin{array}{l}\text { No. } \\
\text { Rek }\end{array}$ & Jumlah & \\
\hline & & & & & & & \\
\hline & & & & & & & \\
\hline
\end{tabular}

Sumber: Diolah

(3) Jurnal Penerimaan Kas

Jurnal penerimaan kas sekaligus sebagai buku kas karena fungsi dan manfaat buku kas sama dengan jurnak penerimaan kas. Sehingga lebih efisien bila dijadikan satu.

Berikut jurnal penerimaan kas yang disarankan dibwah ini:

Tabel 2

Jurnal Penerimaan Kas yang Disarankan

\begin{tabular}{|c|c|c|c|c|c|c|c|}
\hline \multicolumn{8}{|c|}{$\begin{array}{l}\text { CV Restu Ibu Banjarmasin } \\
\text { Jurnal Penerimaan kas } \\
\text { Juli } 2013\end{array}$} \\
\hline \multirow[t]{2}{*}{ Tanggal } & \multirow[t]{2}{*}{ Keterangan } & \multirow{2}{*}{$\begin{array}{c}\text { No } \\
\text { Bukti }\end{array}$} & \multirow{2}{*}{$\begin{array}{l}\text { Piutang } \\
\text { Dagang } \\
\text { kredit }\end{array}$} & \multirow{2}{*}{$\begin{array}{l}\text { Penjualan } \\
\text { Tunai } \\
\text { Kredit }\end{array}$} & \multicolumn{2}{|c|}{ Lain-lain kredit } & \multirow{2}{*}{$\begin{array}{c}\text { Kas } \\
\text { Debit }\end{array}$} \\
\hline & & & & & $\begin{array}{l}\text { No. } \\
\text { Rek }\end{array}$ & Jumlah & \\
\hline & & & & & & & \\
\hline & & & & & & & \\
\hline
\end{tabular}

Sumber: Diolah

(4) Kartu Persediaan

Kartu persediaan memiliki manfaat diantaranya selain mencatat berkurangnya harga pokok produk yang dijual, disamping itu untuk mengawasi mutasi dan persediaan barang yang disimpan. 
Tabel 3

Kartu Persediaan yang Disarankan

\begin{tabular}{|c|c|c|c|c|c|c|c|c|c|}
\hline \multicolumn{9}{|c|}{$\begin{array}{c}\text { CV Restu Ibu Banjarmasin } \\
\text { Kartu Persediaan } \\
\text { Juli 2013 }\end{array}$} \\
\hline \multirow{2}{*}{ Tanggal } & \multicolumn{3}{|c|}{ Pembelian } & \multicolumn{3}{|c|}{ Penjualan } & \multicolumn{3}{c|}{ Saldo } \\
\cline { 2 - 10 } & Harga & Unit & Jumlah & Harga & Unit & Jumlah & Harga & Unit & Jumlah \\
\hline & & & & & & & & & \\
\hline & & & & & & & & & \\
\hline
\end{tabular}

Sumber: Diolah

\section{KESIMPULAN}

Dalam penyelenggara kegiatan di lingkungan perusahaan terutama pada penerapan sistem penerimaan kas dari penjualan tunai, penulis menyimpulkan:

(1) Dilihat dari tugas masing-masing karyawan sebaiknya dilakukan pemisahan fungsifungsi agar dapat mengefektifkan semua karyawan dan tidak terjadi lagi perangkapan fungsi yaitu dengan menambahnya karyawan semua kegiatan perusahaan tetap terkendali berjalan dengan lancar dan baik.

(2) Uraian tugas lebih jelas dan setiap bagian dalam perusahaan dapat lebih di efektifkan yaitu pimpinan melaksanakan fungsi kas, wakil pimpinan melaksanakan fungsi akuntansi, satu orang khusus menangani fungsi penjualan untuk melayani pembeli.

(3) Pencatatan yang sangat tidak memadai sehingga menyulitkan pimpinan dalam mengontrol operasional dan keluar masuknya kas perusahaan sebaiknya CV Restu Ibu Banjarmasin memiliki pencatatan penjualan tunai, penerimaan kas dan harga pokok penjualan agar perusahaan dapat mengetahui berapa besar penerimaan kas yang diperoleh dari hasil penjualan barang serta laba atau rugi.

(4) Perlu dibuatkan kolom khusus untuk mencatat setiap transaksi, dengan penggunaan jurnal khusus memungkinkan beberapa karyawan mencatat dengan segera berbagai transaksi yang terjadi dalam perusahaan tersebut.

(5) Dalam rangka melindungi atau menjaga uang kas yang dimiliki CV Restu Ibu Banjarmasin, maka sebaiknya uang kas yang diterima segera disetorkan ke bank secara periodik. 


\section{DAFTAR PUSTAKA}

Baridwan, Zaki. 2009. Sistem Akuntansi. Edisi 6. Yogyakarta: Penerbit BPFE.

Ikatan Akuntansi Indonesia. 2010. Standar Akuntan Keuangan. Jakarta: Salemba Empat.

Mulyadi. 2005. Sistem Akuntansi. Edisi 4. Yogyakarta: STIE YKPN.

Supriyono. 2004. Akuntansi Manajemen. Edisi 3. Yogyakarta: STIE YKPN.

Tunggal, Amin Widjaja. 2005. Sistem Pengendalian Manajemen. Jakarta: Rineka Cipta. 